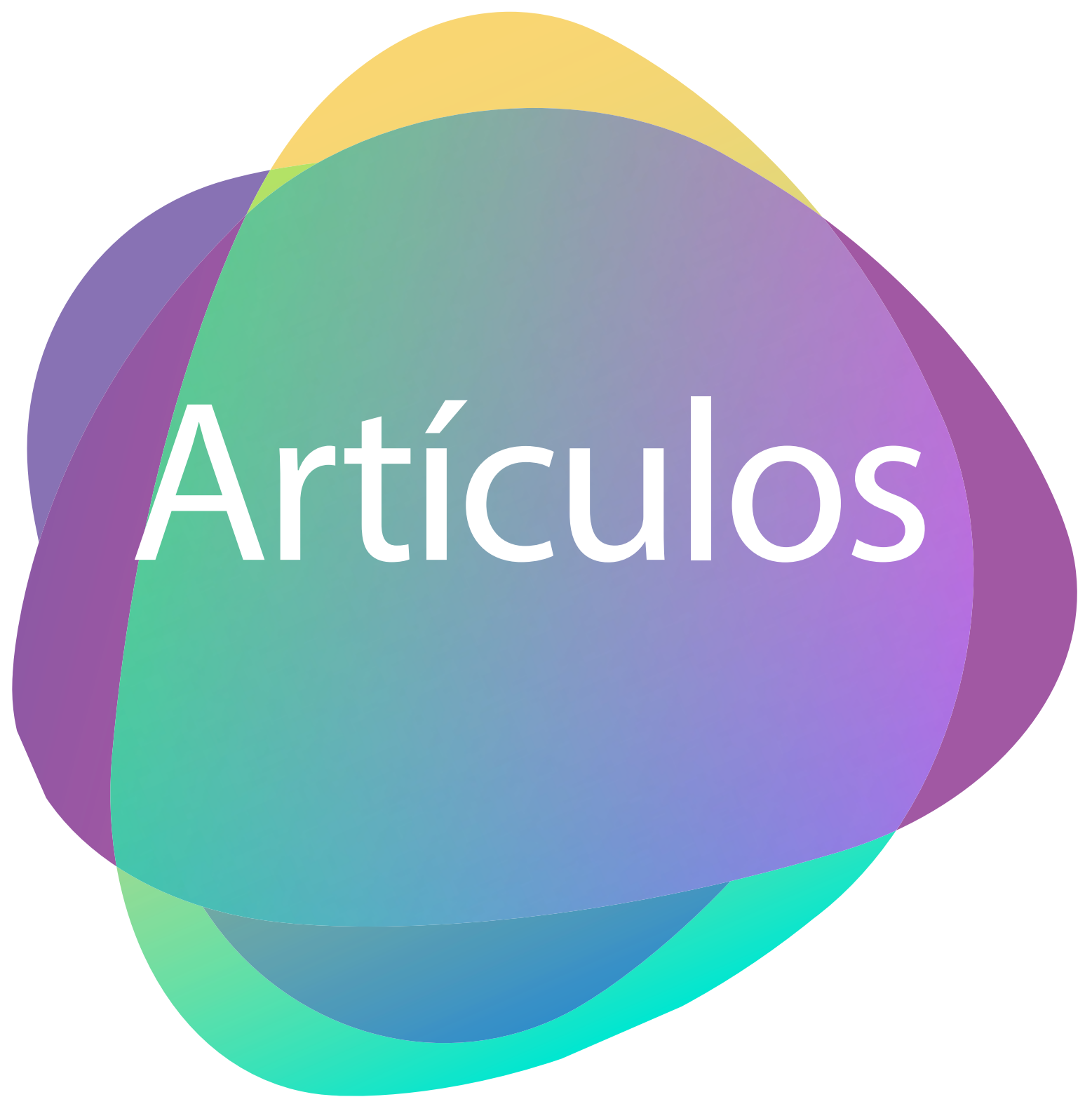




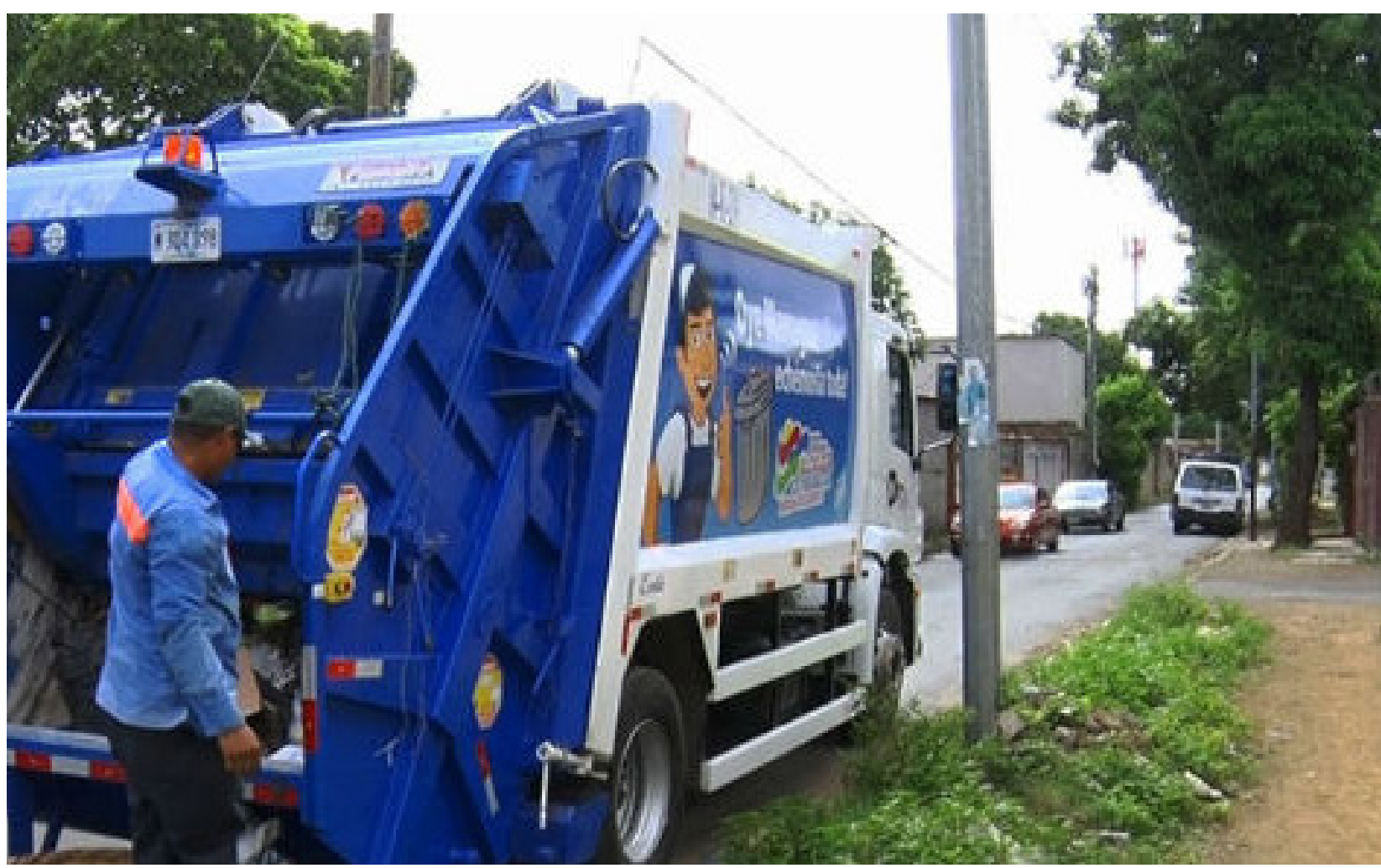

\section{Manejo actual de los residuos sólidos no peligrosos en el complejo Ciudad Belén; distrito VI del Municipio de Managua.}

Hanio Iván Baquedano Uriarte.

Licenciado en Geografía, UNAN MANAGUA, Departamento de Geografía https://orcid.org/0000-0002-0752-7337

Jhaniorsuriarte27@outlook.com

Lisseth Carolina Blandon Chavarría

Master en Ciencias del agua con énfasis en calidad. UNAN MANAGUA, Departamento de Geografía.

https://orcid.org/0000-0003-4125-0332

lizzblandon@gmail.com 


\section{Manejo actual de los residuos sólidos no peligrosos en el complejo Ciudad Belén; distrito VI del Municipio de Managua.}

\author{
Current management of non-hazardous solid waste in \\ the Ciudad Belén complex; District VI of the municipality \\ of Managua.
}

\section{RESUMEN}

El proyecto complejo habitacional Ciudad Belén, está ubicada en el distrito VI del municipio de Managua. El área de estudio está compuesta por 4 etapas, albergando un total de 15,000 habitantes, distribuidos en 2,266 casas. Actualmente se observan malas prácticas por parte de los habitantes con respecto a la gestión de los residuos sólidos (GIRS), no peligrosos, lo que provocó la creación de vertederos ilegales en la periferia y dentro del complejo; evidenciado por la exposición de grandes cantidades de basura al aire libre (focos de contaminación), que originan problemas ambientales. Para determinar el tipo de manejo que realizan los habitantes de Ciudad Belén, se diseñó y aplico instrumentos para el levantamiento de información cualitativa y cuantitativa referido a: Peso, Volumen, Densidad, PPC y manejo de los residuos.

\section{ABSTRACT}

The Ciudad Belén housing complex project is located in District VI of the municipality of Managua. The study area is composed of 4 stages, housing a total of 15,000 inhabitants, distributed in 2,266 houses. The inhabitants perform bad practices with regard to the management of solid waste (GIRS), non-hazardous, which causes the emergence of illegal landfills in the periphery and within the complex, evidenced by the exposure of large amounts of outdoor garbage (foci of pollution), which cause environmental problems. To determine the type of management carried out by the inhabitants of Ciudad Belén, instruments were designed and applied to collect qualitative and quantitative information regarding: Weight, Volume, Density, PPC and waste management.

\section{PALABRAS CLAVE}

Manejo, Residuos, Población.

\section{KEYWORDS}

Management, Waste, Population. 


\section{Introducción}

El origen del problema de la GIRS en Nicaragua está en la generación de los residuos, la poca o nula separación de la fuente, reusó y reciclaje, así como, la poca capacidad de la recolección, transporte, tratamiento y disposición final por parte de las autoridades competentes, (residuos Sólidos no peligrosos- municipales-, residuos sólidos peligrosos-entes centrales. (MARENA-CCAD, 2011)

Con relación al problema de la generación de residuos a nivel nacional, se estima que la generación total de residuos sólidos es de 3,500 Ton/día, lo que equivale a una producción de 1, 600 Ton/ día, con una PPC de $0.7 \mathrm{Kg} / \mathrm{Hab} /$ día y para el resto del país se ha considerado una producción por habitantes de $0.45 \mathrm{Kg} /$ Hab/día, en el área urbana.

Las soluciones a los problemas derivados del manejo inadecuado implican relaciones interdisciplinarias complejas entre campos como la ciencia política, el urbanismo, la planificación regional, la geografía, la economía, la salud pública, la sociología, la demografía, las comunicaciones y la conservación, así como la ingeniería y la ciencia de los materiales (Tchobanoglous, 2006). La falta de educación ambiental, así como la sensibilización y sentido de conciencia por parte de la población, es un factor que influye de forma negativa en la producción y la generación de desechos. Otro factor importante es el nivel educativo, así como el estilo de vida de los habitantes del complejo. Acciones en las cuales se forje la conciencia ambiental tales como: reciclaje y la reutilización, de los desechos generarían cambios significativos en el medio.

Por lo anterior se plantea que:

El manejo inadecuado de los Residuos sólidos no peligrosos por los habitantes influye en la creación de vertederos ilegales dentro y en la periferia del complejo habitacional Ciudad Belén, distrito VI del Municipio de Managua.

El objetivo primordial de este trabajo es determinar el tipo de manejo que los habitantes de Ciudad Belén realizan con respecto a la generación de los residuos sólidos y sobre los resultados diseñar estrategias que contribuyan a mejorar el manejo en la gestión integral de los residuos sólidos no peligrosos en el área de estudio.

\section{MATERIALES Y MÉTODOS.}

\section{Tipo de investigación}

La investigación es explicativa tomando en cuenta que, fue necesario la estimación de las variables: Densidad, PPC, Peso, Volumen; y como lo generado se relaciona con el actual manejo por parte de los habitantes de ciudad Belén.

\section{Fuentes y técnicas de recopilación de datos.}

Para conocer el manejo que los habitantes de Ciudad Belén realizan con respecto a los residuos sólidos no peligrosos, fue necesario el diseño y aplicación de una encuesta estructurada en cuatro acápites: (1)Datos personales (2) Grado de conocimientos (teóricos) sobre manejo de los residuos sólidos (3) Aspectos sociales 
y económicos (4) Actividades de manejo que realizan los habitantes de Ciudad Belén.

En lo que respecta al trabajo de campo se tomo como muestra residuos sólidos no peligrosos en 45 casas por un periodo de siete días consecutivos. El muestreo consistió en proporcionar a los habitantes 2 bolsas plásticas etiquetadas cada una de ellas con orgánicos e inorgánicos, explicándole cual debía ser el tipo de separación debían hacer para efectos del muestreo.

- Determinación de la Muestra. Para determinar la muestra según (Lacayo;Lopez, 2009), el tamaño de la muestra debe de estar constituido por el 2 y $6 \%$ del total de habitantes presentes en el área de estudio. Para efectos de esta investigación se tomó el $2 \%$ del total de viviendas en el complejo habitacional Ciudad Belén. En la ilustración 1 se observa con puntos rojos marcado las casas muestreadas.

Muestra $=\frac{\text { Total de viviendas }(2 \%)}{100}=$

$$
\text { no }=\frac{2266(2)^{2}}{100}=45.32 \text { Casas. }=45 \text { casas }
$$

llustración 1: Distribución del universo y muestra de investigación.

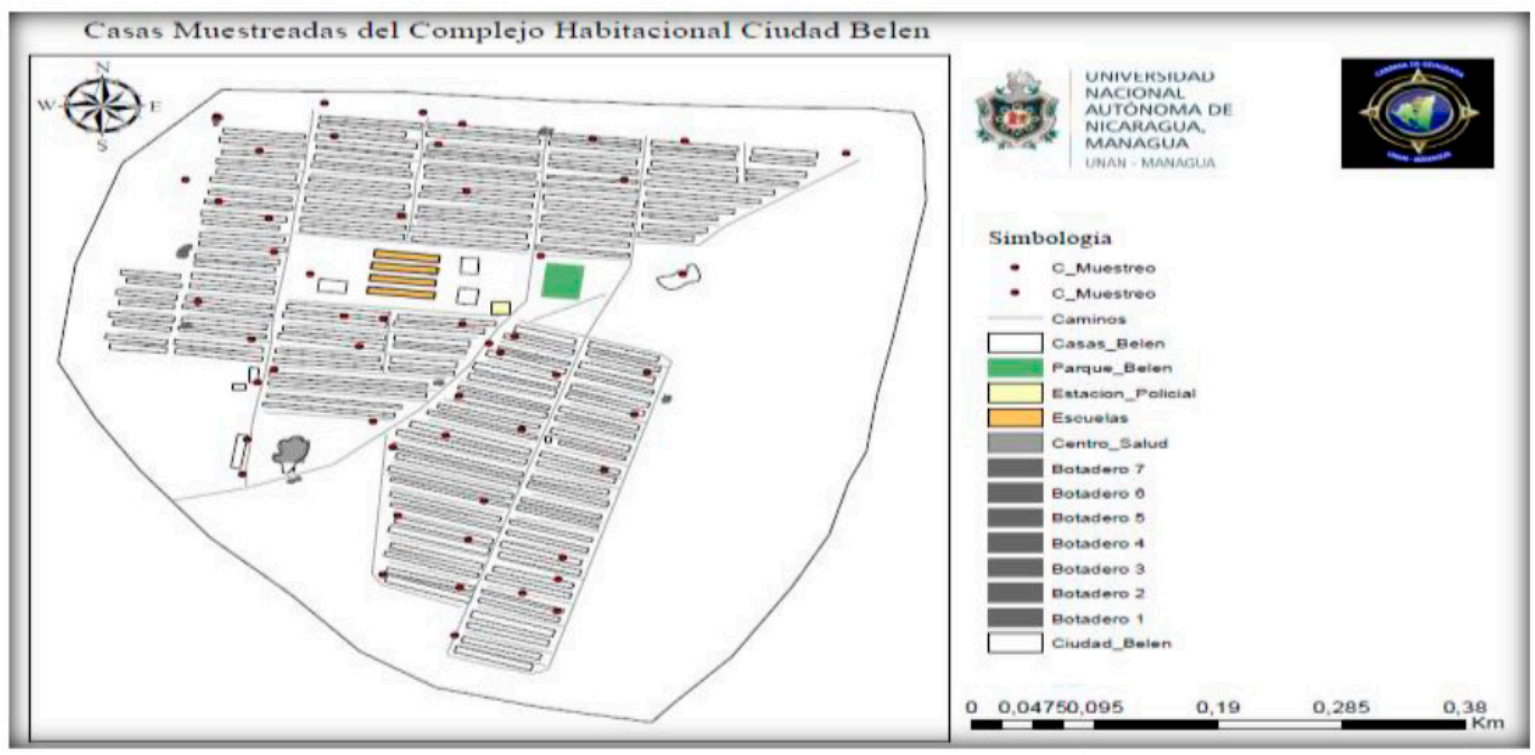

Mapa 1: Distribución del universo y muestra de investigación representada en plano habitacional. 


\section{Ubicación , extension y límites}

El complejo habitacional Ciudad Belén tiene una extensión territorial de $0.54 \mathrm{~km} 2$ y tiene los siguientes límites: f) Incumpla gravemente los deberes de su cargo para facilitar las conductas descritas en los literales anteriores".

\begin{tabular}{|l|l|}
\hline \multicolumn{2}{|c|}{ Datos Geográficos } \\
\hline $\begin{array}{l}\text { Coordenadas } \\
\text { UTM }\end{array}$ & X: $591557 \mathrm{~m} \mathrm{E}$ \\
Ylevación & \multicolumn{1}{|c|}{$68 \mathrm{~m}$.s.n.m.m } \\
\hline Limites geográfico de la comarca \\
\hline Norte & $\begin{array}{l}\text { Aeropuerto Internacional Augusto C. Sandino y } \\
\text { Carretera Norte. }\end{array}$ \\
\hline Sur & Sabana Grande. \\
\hline Este & Barrió Cofradia y Los Reyes. \\
\hline Oeste & Barrió Villa Dignidad. \\
\hline
\end{tabular}

\section{RESULTADOS Y DISCUSIÓN}

\section{Características socio-económicas.}

En investigaciones vinculada al manejo de los residuos sólidos es importante realizar un análisis de las características sociales y económicas que permitan acercarnos a la realidad del manejo actual de los residuos y el modo de vivir de las familias de ciudad Belén.

\section{Contexto histórico del complejo ciudad Belén.}

Como respuesta a la urgente necesidad de viviendas que presentaban familias ubicadas en áreas altamente vulnerables o zonas de riesgo a: deslizamiento, inundaciones, así como familias en extrema pobreza, damnificados por eventos Naturales, al igual familias afectadas por obras de infraestructura de la capital, el gobierno de Nicaragua ejecuto el programa ("Complejo Ciudad Belén"), fue así que a través de la alcaldía de Managua se construyó inicialmente el complejo de ciudad Belén con aproximadamente 1,700 viviendas, todas ellas entregadas a los protagonistas.

En años siguientes, la demanda de viviendas ha incrementado hasta alcanzar actualmente la cantidad de 2, 266 viviendas en el complejo; de este modo a medida que la población ha incrementado paralelamente han aumentado los problemas ambientales; entre ellos el manejo ineficiente de los desechos sólidos de parte de la población.

\section{Organización social}

El Complejo Habitacional Ciudad Belén cuenta con el Consejo de Liderazgo Sandinista (CLS), conformado por los mismos habitantes de Belén, siendo así ellos los representantes y responsables de recoger y dirigir las diferentes problemáticas y peticiones para notificadas a la alcaldía de Managua. Del mismo modo dentro del centro se encuentra organizada la cooperativa de trasporte de 3 ruedas(mototaxis) 
"Compañero Rene Núñez", las que ofrecen el servicio de trasporte dentro y en los alrededores del complejo. Dentro del complejo se pudo evidenciar que existe presencia institucional del estado entre ellos están: La estación policial ubicada frente al parque público de Belén, un Centro de Salud Familiar y Comunitario Ciudad Belén II, encargado de atender las familias de Belén, un centro escolar de modalidad primaria y secundaria que brinda el servicio a toda la población en general; contigo al colegio esta un Centro de Desarrollo Infantil (CDI) donde brinda el cuido de infantes y modalidad preescolar. La obra (complejo habitacional Ciudad Belén) trae integrado áreas verdes, así como un parque de recreación comunitaria, en las que se desarrollan actividades de recreación familiar para todo el que desee llegar.

\section{Población Sexo, edad y total de habitantes}

La población de Ciudad Belén está agrupada principalmente en 6 rangos de edad-Sexo; mujeres de 15-30, constituyen un $22 \%$ de los habitantes totales, mujeres de $30-45$, alcanzando un $22 \%$, mujeres de $45-70$ años o más con $14 \%$. En lo que respecta a varones las edades van entre 15-30 años con 11\%, de la población, varones de 30-45 años con un $20 \%$ y el restante que corresponde al $11 \%$ son varones de $45-70$ de la población total.

\section{Principales actividades económicas}

Dentro de las principales fuentes de empleos de los habitantes de Ciudad Belén las mostraron que el 27\% Se dedican al comercio (Pulperías en casa) en lo que respecta al $6 \%$ comerciantes en el mercado oriental, $13 \%$ representa empleo formal en empresas privadas un $2 \%$ trabaja para el estado, siendo un $45 \%$ tienen trabajos propios informales de este $45 \%$ un $27 \%$ su principal fuente de empleo es ser recolectores o carretoneros de basura. Esta basura recolectada posteriormente es depositada en los diferentes vertederos a cielo abierto existentes en el complejo,yfinalmenteel7\%trabajanenlimpiezadehogares, electricistas, fontaneros,ocargadoresenlosmercados.

La población de Ciudad Belén, es una población de difícil tratar esto se debe a que ellos aducen sentirse excluidos de la sociedad (Población de Managua), posterior a la reubicación, la población se adecuo a sus nuevos lugares de residencias y desempeñaron las mismas actividades que antes de ser trasladados realizaban, lo que produjo las iniciativas de pequeñas pulperías de abarrotes dentro del complejo.

Las áreas de trabajos de los acarreadores de Ciudad Belén, comprenden principalmente las áreas periféricas del complejo, entre ellas esta, Sabana Grande, Villa Libertad, Carretera Norte, siendo así que parte de la basura que se genera en los botaderos no es producida por los habitantes del complejo, es trasladad por los acarreadores para la respectiva selección de residuos solidos no peligros que representan valor monetario.

Los recolectores y acarreadores, cuando están en sus horas laborales no hacen uso del centro de transferencia administrado por la alcaldía, en cambio obstan por depositarlas dentro del mismo complejo, generando los botaderos a cielo abierto existentes en Ciudad Belén, esto último podría ser una de las causas de los vertederos ilegales a cielo abierto en el área en estudio.

\section{Manejo de residuos sólidos no peligros}

En lo que compete al manejo de los residuos sólidos por parte de los habitantes de Ciudad Belén, se abordó acerca del tipo de manejo que le daba a los desechos que generaban (basura), dando como resultado que un $60 \%$ de la muestra aduce entregarla al tren de aseo, ya que para ellos es lo más fácil y correcto; es importante mencionar que este $60 \%$ obedece a las familias que por su ubicación tienen el servicio de recolección 3 veces por semana; un $10 \%$ la disponen en los vertederos ilegales cercanos a sus hogares, un $10 \%$ aduce enterrarlas y un 
$20 \%$ de la población dijo quemarla, lo cual según la NORMA TÉCNICA Nº. NTON 05 014-02, en el apartado 17.2 establece que: “No se permite la quema de desechos sólidos no peligrosos, bajo ninguna circunstancia”.

\section{Conocimiento sobre el reciclaje}

Se les preguntó a los habitantes ¿si conocían el termino de reciclaje y lo que conllevaba en la práctica? (Ver. Gráfico 1); un $50 \%$ de la muestra opino no saber acerca de reciclaje y cómo funcionaba el mismo, un $30 \%$ dijo conocer sobre el reciclaje y ponerlo en práctica en sus hogares y un $20 \%$ dijo no estar segura, en algunos de los casos les parecía haberlo visto en publicaciones en las redes sociales o en algún tipo de reunión familiar y escolar.

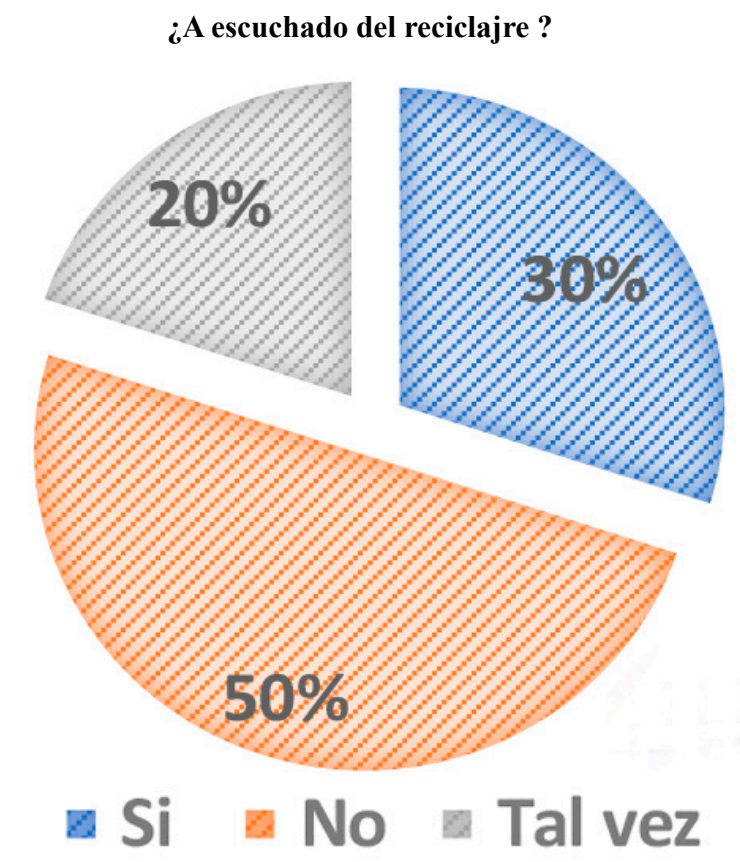

\section{Practica el reciclaje}

Del mismo modo, se les pregunto sobre si aplicaban el reciclaje como estilo de vida dentro de sus vidas cotidianas (Ver gráfico 1) dando como resultado que un $50 \%$ de la muestra adujo hacer reciclaje esporádicamente de algunos residuos que normalmente más generaban(plásticos), un $30 \%$ dijo que si ponían en práctica el reciclaje y un $20 \%$ dijo no hacerlo que para ellos resultaba una pérdida de tiempo y algo innecesario.

En lo que respecta al conocimiento del término "reciclaje" y la acción del mismo, se puede ver que existe una contradicción (ver, grafico 2 y 3), esto obedece a la magnitud de lo que para la población de Belén es Reciclar, otra causa podría ser que las familias por no atribuirse los problemas del mal manejo de los residuos no seleccionaron la respuesta correcta en la rúbrica, lo que se evidencia en la contradicción de las respuestas proporcionadas por ellos mismo. 


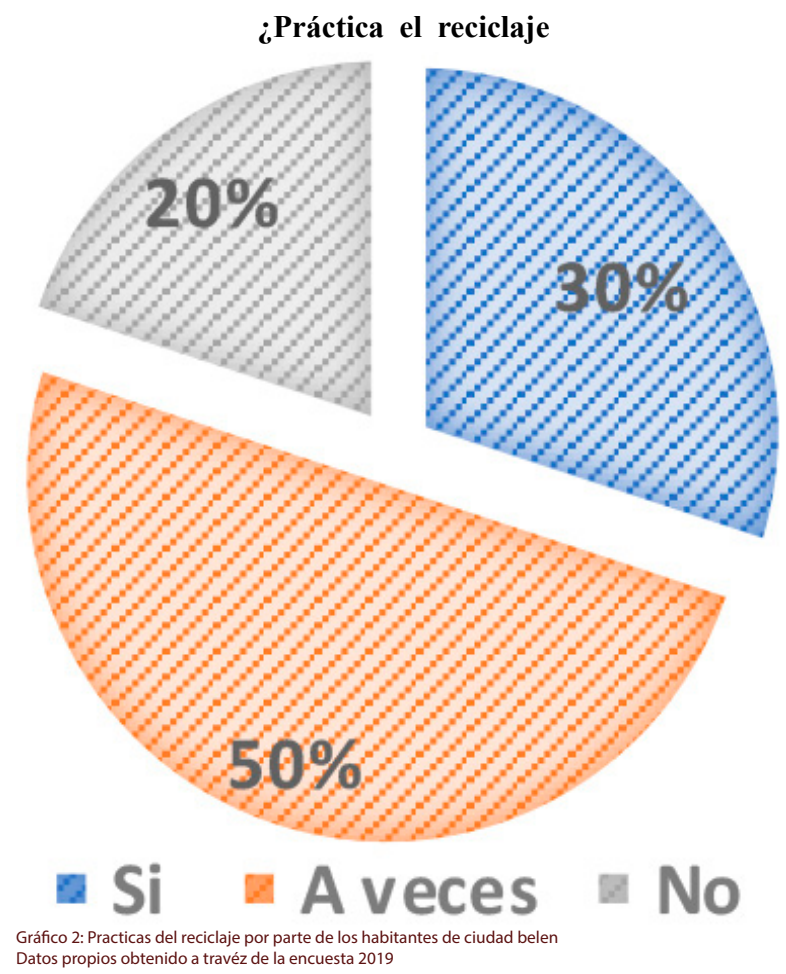

Generación de vertederos ilegales dentro y en la periferia del complejo.

Según la población el problema en la generación de nuevos vertederos ilegales dentro y en la periferia del complejo, obedece a que un $50 \%$ de la muestra aducen no tener conciencia y educación ambiental, un $30 \%$ expreso que la culpa es de todos, tanto de autoridades como de la población en general, un 15\% dijo que era de personas externas del complejo (vecinos de los barrios cercanos) y un $5 \%$ dijo no saber.

A demás de ello el $70 \%$ de la muestra dijo que hay problemas serios con el manejo de los residuos y es algo muy visible, que solo bastaría con dar un recorrido por el área para poder notarlo. Posterior se consultó a la población sobre ¿De quién era la responsabilidad de la creación de vertederos ilegales?

El 50\% de la muestra se la atribuyen a los mismos habitantes de Ciudad Belén, aduciendo que la población no tiene conciencia, ni una educación ambiental, un 30\% expresó que la culpa es de todos, tanto de autoridades como de la población en general, un 15\% dijo que era de personas externas del complejo (vecinos de los barrios cercanos) y un $5 \%$ dijo no saber.

\section{Disposición final de los residuos y áreas críticas de Ciudad Belén.}

En el complejo habitacional Ciudad Belén, las fuentes generadoras de residuos sólidos, son principalmente las casas, si a eso se le suma que el $27 \%$ de la población activa se dedica a la recolección de los residuos (carretoneros), que se generan en los alrededores del complejo y que posterior son dispuestos sin ningún tipo de tratamiento en las calles del complejo, los alrededores y el cauce que limita al lado este del complejo. Esto trae consigo la generación de pequeños botaderos al cielo abierto distribuidos en diferentes partes del área en estudio. 
Uno de los principales vertederos a cielo abierto se ubica en el extremo sur del complejo directamente el cauce, un segundo en la segunda calle y el resto están distribuidos en el complejo (Ver mapa 1: Ubicación de los vertederos). Dentro de las causas que expresan la población en cuanto a la creación del vertedero dentro del cauce; es la ausencia del tren de aseo en esta zona debido al difícil acceso; es por ello que los habitantes explican que no tiene otra alternativa que depositarla al cauce.

En el mapa 1 se observa que en total existen 7 vertederos los cuales ocupan áreas como máximo de $287.1 \mathrm{~m} 2$ y un minino de $1424.1 \mathrm{~m} 2$.

Es importante mencionar que el área en estudio existe un centro de transferencia que fue habilitado, pero al consultar a la población; el $80 \%$ de la muestra expreso que les queda demasiado lejos y es una pérdida de tiempo teniendo el servicio de recolección del tren de aseo, un 15\% lo mira innecesario y un 5\% aduce que, si hace uso del mismo, pero esporádicamente solo cuando tenían que eliminar volúmenes grandes de residuos por semana, lo cual es coincidente con el $76 \%$ de las respuestas obtenidas en la encuesta.

Dentro de las mismas se abordó el nivel de satisfacción de parte de la población con las cantidades de veces que transcurre el tren de aseo; siendo así un 50\% de la población dijo no estar de acuerdo, algunas de ellas se deben a que por su cuadra el tren de aseo solo pasa una vez por semana o inclusive no pasa, un $33 \%$ de ellos dijo está de acuerdo, la mayor de ella ubicada en la parte central del complejo siendo de este modo el fácil acceso del tren de aseo, y un 16\% de ellas sugiere que deberían de pasar con mayor frecuencia.

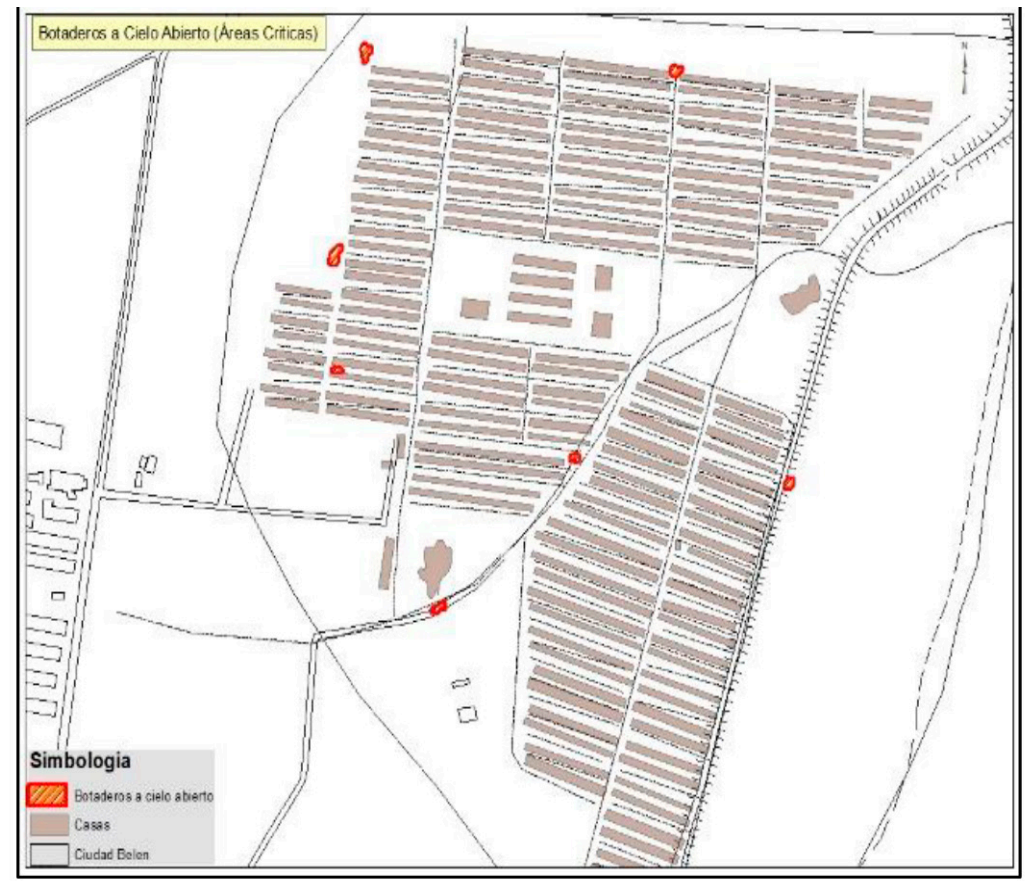

Mapa 2: Distribución del universo y muestra de investigación representada en plano habitacional. Fuente: Elaborada por los autores. 


\section{Probable origen de los vertederos.}

La población de Ciudad Belén, es una población que manifestó sentirse excluidos de la sociedad (población de Managua), los orígenes y ocupaciones de las familias son variados, entre los probab

El 27\% de la población que actualmente son trabajadores por cuenta propias, se dedican a la recolección y acarreo de la basura, una de las principales causas es que gran parte de la población carece de educación superior, y por lo tanto se es difícil el aplicar a trabajos que sean regulados por la ley.

Las áreas de trabajos de los acarreadores de Ciudad Belén, comprenden principalmente las áreas periféricas del complejo, entre ellas esta, Sabana Grande, Villa Libertad, Carretera Norte, siendo así que parte de la basura que se genera en los botaderos no son producidos por los habitantes de Belén, todo lo contrario, la basura es generada por la fuente de empleo de los acarreadores y recolectores de basura.

Los recolectores y acarreadores, cuando están en sus horas laborales no hacen uso del centro de transferencia administrado por la alcaldía, en cambio optan por depositarlas dentro del mismo complejo, generando los botaderos a cielo abierto existentes en Ciudad Belén.

Dentro de las soluciones que proponen los habitantes para mejorar la situación actual se encuentra:

1. Capacitación sobre el manejo de los residuos sólidos no peligrosos.

2. Regulación de la actual fuente de trabajo de los acarreadores, el cual debe ir acompañado de un plan que contenga la generación de nuevos empleos.

3. Creación de un nuevos centros de transferencia que cumpla con las necesidades de los habitantes entre ellos solicitan: Ubicación pero lo más importante es crear conciencia en la nueva generación del complejo, educándolos con sentidos de pertenencia de los recursos, sensibilidad, pero sobre todo amor a la naturaleza

\section{Conclusiones}

A través de la aplicación de encuestas y conversaciones con los habitantes se logró identificar que los sietes botaderos a cielo a abierto tiene su origen en aspectos socioeconómicos presentes en el área, entre ellos destaca:

1. El bajo nivel educacional de la mayoría de los habitantes; es importante mencionar que esto no esta asociado a la cobertura por parte del Gobierno, dado que dentro del complejo cuenta con una colegio que reúne educación inicial, primaria y secundaria.

2. La fuente de empleo (recolectores) histórica y actual del $27 \%$ de los habitantes del complejo.

3. La carencia de una cultura de cuido al ambiente y protección del los recurso, lo cual esta asociado directamente con los actuales niveles de educación presente en la zona. 
4. La infraestructura vial deficiente que no permite el acceso al tren de aseo, es una de las causas actuales de porque el cauce es una zona de disposición final de los residuos solidos no peligrosos por parte de los habitantes.

5. El centro de transferencia que fue creado con el objetivo de ser sitio de disposición final de los residuos, actualmente no cumple esa función, porque los habitantes lo consideran demasiado alejado para ir a depositar sus residuos.

\section{Agradecimientos}

A la universidad Nacional autónoma de Nicaragua, en especial al departamento de Geografía. A los colaboradores: Dr. Samantha Espinoza, MSc. Rafael Varela y MSc. Ingrid Úbeda Trujillo, Esther Salguera y Uriel Morales.

Al Ministerio del Ambiente y los Recursos Naturales-MARENA.

\section{Referencias bibliográficas}

- Asamblea Nacional (2003). Constitución Política de la Republica de Nicaragua sus Reformas Consultado en diciembre 05, 2018 en

- $\quad$ Asamblea Nacional (1996). Ley 217: Ley General del Medio Ambiente y los Recursos Naturales. La Gaceta Diario Oficial. Managua, Nicaragua.

- $\quad$ Asamblea Nacional (2005). Ley 559: Ley Especial de Delitos contra el Medio Ambiente. La Gaceta Diario Oficial. Managua, Nicaragua.

- $\quad$ Asamblea Nacional (1996). Decreto 9-96: Reglamento de la Ley General del Medio Ambiente y los Recursos Naturales. La Gaceta Diario Oficial. Managua, Nicaragua.

- Asamblea Nacional (2005). Decreto 47-05: Política Nacional de Manejo de los Residuos Sólidos. La Gaceta Diario Oficial. Managua, Nicaragua.

- Asamblea Nacional (2002). NTON 05 014-01: Norma Técnica Ambiental para el Manejo, Tratamiento y Disposición final de los Residuos No Peligrosos. La Gaceta Diario Oficial. Managua, Nicaragua.

- Contreras, Velásquez Hernández, (2016) propuesta para el manejo a los residuos sólidos generados en la plaza de mercado del casco urbano del municipio de la mesa Cundinamarca.

- Banco Interamericano de Desarrollo (1997). Guía para Evaluación de Impacto Ambiental para Proyectos de Residuos Sólidos Municipales, Procedimientos Básicos. BIC.

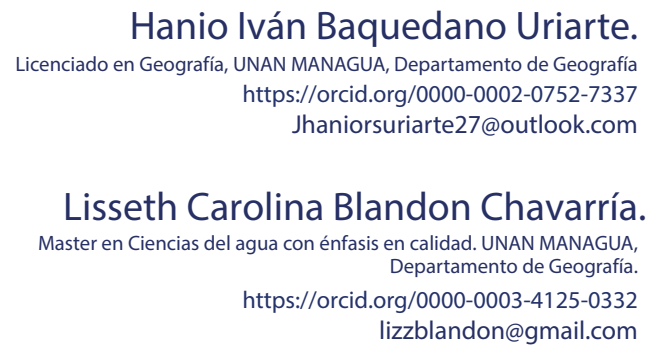

